\title{
Perkütan endoskopik gastrostomi tüpünün nadir komplikasyonu: Nekrotizan fasiit
}

\section{A rare complication of percutaneous endoscopic gastrostomy: Necrotizing fasciitis}

\section{(D) Güldan KAHVECI ${ }^{1}$, (D) Selma DAĞCI ${ }^{2}$, (D Roni ATALAY ${ }^{3}$}

Ümraniye Eğitim ve Araștırma Hastanesi, ${ }^{1}$ Nutrisyon Hemşireliği Bölümü, Istanbul Istanbul Il Sağllk Müdürlüğü, ${ }^{2}$ Kamu Hastaneleri Hizmetleri Başkanllğı-2, Istanbul Ankara Bilkent Şehir Hastanesi, ${ }^{3}$ Gastroenteroloji Kliniǧri, Ankara

Perkütan endoskopik gastrostomi çeșitli nedenlerden dolayı uzun süre ağızdan beslenemeyen hastalara, gastrointestinal sistem fonksiyonel ise sedasyon altında beslenme tüpünün perkütan olarak mideye yerleștirilmesi ișlemidir. Perkütan endoskopik gastrostomi minör ve majör komplikasyonlara neden olabilir. Nekrotizan fasiit, yüzeyel fasia ve deri altı dokuyu tutan yumuşak doku enfeksiyonu olmakla birlikte, nadir görülen ancak ölümle sonuçlanabilen majör komplikasyonlardan biridir. Hasta/bakım vericinin uygun eğitimi ve hastaneden taburcu olduktan sonra bakımın sürekliliği perkütan endoskopik gastrostomi tüpünün uzun süreli kullanımı için önemlidir. Komplikasyonların çoğu, bakımın kalitesine bağlıdır ve uygun önlemler alınırsa etkili bir şekilde önlenebilir. Bu makalede perkütan endoskopik gastrostominin nadir ve mortal seyredebilen majör komplikasyonu olan nekrotizan fasiitli olgu sunulmuştur. Bu olgu sunumu vesilesi ile perkütan endoskopik gastrostominin mortal seyredebilen majör komplikasyonlarnın hemşireler tarafından alınacak önleyici tedbirler ile maliyet etkin bir şekilde önlenebileceği literatür ışığında vurgulanması amaçlanmıştır.

Anahtar kelimeler: Perkütan endoskopik gastrostomi, nekrotizan fasiit, majör komplikasyon, enteral beslenme, hemşirelik bakımı
Percutaneous endoscopic gastrostomy is a procedure where a feeding tube is passed percutaneously into the patient's stomach under sedation. The procedure is carried out on patients whose gastrointestinal system is functional and, for various reasons, cannot be fed orally for a long time. Percutaneous endoscopic gastrostomy can cause minor and major complications. One of the rare but fatal major complications is necrotizing fasciitis. It is a soft tissue infection that involves the superficial fascia and subcutaneous tissue. Proper training of the patient/caregiver and continuity of care after discharge from the hospital are important for long-term use of the percutaneous endoscopic gastrostomy tube. Most complications can be effectively prevented if a high quality of care is present and appropriate measures are taken. In this article, a case of nectotizing fasciitis, a rare and mortal complication of percutaneous endoscopic gastroscopy, is presented. This case report aims to emphasize the major complications of percutaneous endoscopic gastrostomy that may progress mortally in the light of the literature that discusses how preventive measures carried out by critical-care nurses can be cost effective.

Keywords: Percutaneous endoscopic gastrostomy, necrotizing fasciitis, major complications, enteral nutrition, nurse care

\section{GİRISS}

Beslenme gereksinimlerini oral yol ile karşılayamayan, fonksiyonel gastrointestinal sisteme sahip, yetersiz beslenen hastalarda enteral beslenme endikedir (1). Enteral beslenme nazogastrik tüp kullanılarak veya gastrostomi yoluyla uygulanabilir. Enteral beslenmenin 6 haftadan daha uzun süre sağlanması gerekiyorsa, perkütan endoskopik gastrostomi (PEG) önerilir (2). PEG ilk olarak 1980 yllında Gauderer tarafından yerleștirilmiştir (3). PEG tüpü yerleştirilmesinden sonra minör ve majör komplikasyonlar gelişebilir. Perkütan endoskopik gastrostomi tüpü yerleştirilmesi sonucu hastaların yaklaşık \%3-40'ında tüp çevresinde mide içeriğinin sızması, peristomal ağnı, tüp tıkanması, peristomal enfeksiyon gibi minör komplikasyonlar görülebilir. Majör komplikasyonlar hastaların \%0.4-4.4'ünde gelişebilir, bunlar ciddi müdahale gerektiren nekrotizan fasiit, mide kanaması, iç organlarda yaralanma ve gömülü tampon sendromudur (4). Literatürde enteral beslenmenin komplikasyonları konusunda birçok çalışmaya rastlanmaktadır. Bazı çalışmalarda hemşirelerin ve bakım vericilerin enteral beslenme komplikasyonları özellik-

le de PEG komplikasyonları konusunda bilgi düzeylerinin düşük olduğu belirtilmektedir $(5,6)$. Nutrisyon hemşireleri, hastaların beslenmesinden sorumlu olan sağlık profesyonelleridir. T.C Sağlık Bakanlığı Hemşirelik Yönetmeliği’ne (2010) göre hemşire; "Hastaların beslenme gereksinimlerini belirler (enteral ve parenteral beslenme), gereksinimlerine göre hemşirelik bakımını planlar ve uygular, beslenmede kullanılan cihazların sterilizasyonunun devamlılığını sağlar" denilmektedir (7). Türkiye Nüfus ve Sağlık Araştırması (TNSA) 2018 verisine göre ülkemizde 65 yaş ve üzeri nüfusun oranı ilk kez \%10'un üzerine çıkmıştır. Yaşlı nüfusun çocuk nüfusa oranla artış içinde olması, toplumdaki sağlık sorunlarının çocukluk çağı hastalıklarından yaşlı nüfusta görülen hastalıklara doğru kaymasına yol açmıştır (8). Yaşlı nüfusun artması özel beslenme yöntemlerinin daha fazla kullanılmasını gerekli kılmaktadır. Hemşirelerin, özellikle özel bilgi ve bakım gerektiren PEG tüpü ile beslenme konularını iyi öğrenmeleri, kanıta dayalı olarak, uygun hemşirelik bakımı vermeleri, birçok komplikasyonun gelişmesini önlemek, hastaların hasta- 
nede kalış sürelerini azaltmak, yaşam kalitelerini yükseltmek bakımından oldukça önemlidir. Bu sunumda PEG'in majör komplikasyonu olan nekrotizan fasiitin önlenmesinde hemşire bakımının önemi, PEG pansumanının nasıl yapıldığı ve öneminin vurgulanması amaciyla PEG sonucu nekrotizan fasiit (NF) gelişen bir olgu literatür taraması ile birlikte sunulmuştur.

\section{OLGU SUNUMU}

Doksan yaşında, kadın, evli ve alzheimer tanılı hasta KS'ye bir ay önce dış merkezde PEG tüpü yerleştirilmiştir. Tüpün yerleştirilişinin 32. gününde PEG bölgesinde kızarıklık ve akıntı bulguları nedeniyle hasta bakım vericileri tarafindan acil servise getirilmiştir. Yatağa bağımlı ve PEG tüpü olan hastanın NF dokusu (Resim 1), nütrisyon hemşiresi tarafından muayenede tespit edilmiş ve nütrisyon destek ekibi tarafından tanı doğrulanmıştır. Enfeksiyon hastalıkları ve mikrobiyoloji kliniğine interne edilen hasta, nütrisyon destek ekibinin hastayı konsültasyonu sonucu hastanın endoskopi ünitesi ile randevusu planlanıp gastroenteroloji uzmanı tarafından PEG

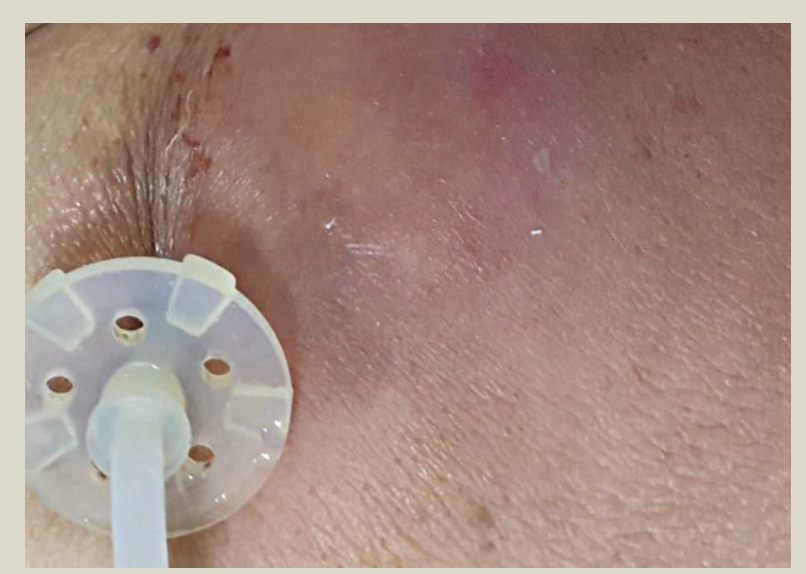

Resim 1. Perkütan endoskopik gastrostomi tüpü çevresinde gelişmiş nekrotizan fasiit.

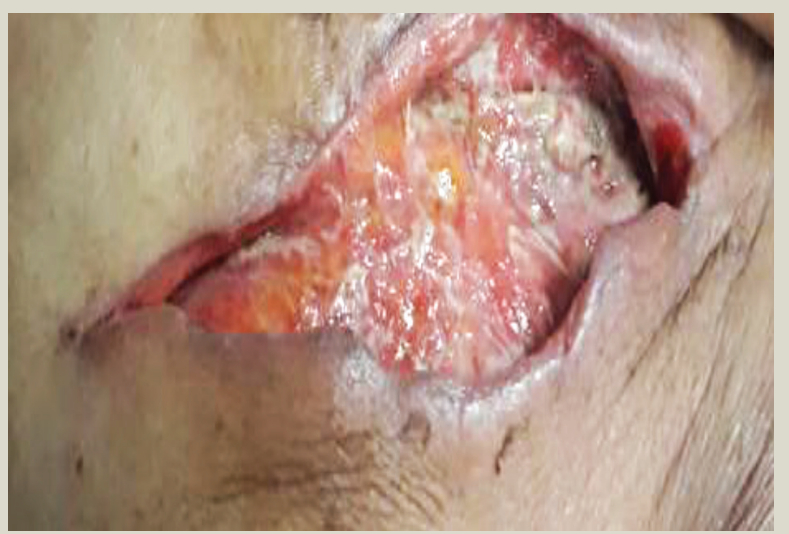

Resim 2. Debridman sonrası doku görünümü.

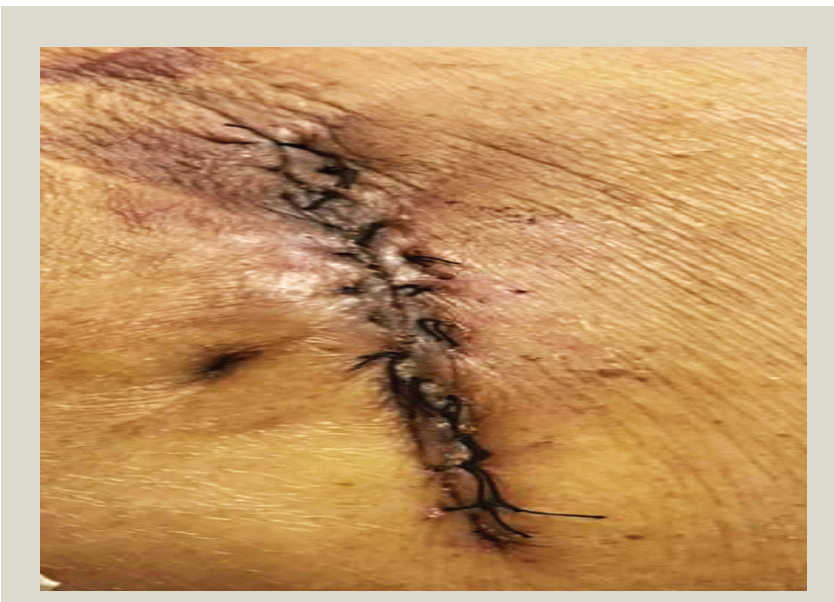

Resim 3. Debridman sonrası sütur ile kapatıldıktan sonraki görünüm.

tüpü çıkarılmış ve akabinde genel cerrahi uzmanı tarafından debridmanı yapılmıştır (Resim 2,3). Bir hafta sonra hastanın nazogastrik tüp ile enteral beslenmesine başlanılmıştır.

\section{TARTIŞMA}

Nekrotizan fasiit, yumuşak doku ve fasyaların nekrozu ile karakterize, hızlı ilerleyen bir hastalıktır. Insidansı yılda 100 bin kişide 0,3 ile 15 arasında bildirilmiştir (9-14). Mortalite oranları \%6-76 gibi geniş bir aralıkta bildirilmiştir. Ayrıca tedavi gecikirse mortalite oranları daha da artmaktadır (15-20).

Nekrotizan fasiit, PEG tüpü yerleşiminin nadir bir komplikasyonudur. Grand ve ark. 2009 yllında PEG tüpü yerleştirilen 129 hastanın l'inde NF geliştiğini bildirmişlerdir (21). Ancak NF gelişimi ölümle sonuçlanabilir. MacLean ve ark. PEG ilişkili NF gelişiminde mortalite oranını \%33 olarak bildirmişlerdir (22). NF; PEG tüpünün çevresinde kabarcıklar, cilt kızarıklı̆ıı, ağrı ve ateş ile ortaya çıkan ani başlangıç ve hızlı ilerleme ile çevredeki yumuşak dokunun ciddi bir iltihabıdır. NF'in klinik evreleri Wang ve ark. tarafindan cilt bulgularına göre erken, orta ve geç olmak üzere 3 evre olarak tanımlanmıştır (Tablo 1). En ileri evredeki cilt bulgusu değişikliği klinik evre olarak alınmalıdır (23). Evre l'de olan; palpasyon ile hassasiyet, eritem, şişme ve deride 1 sı artışı bulguları selülit gibi şiddetli yumuşak doku enfeksiyonları ile benzer olduğundan erken evrede NF tanısı koymak güçleşmektedir. NF mortal seyredebileceğinden, Evre l'de selülit ile NF ayrımı dikkatle yapılmalıdır. Enfekte bölgede birden fazla bakteri bulunabilir (24). Nekrotizan fasiit gelişmesinin risk faktörleri arasında gastrostomi tüpünün yerinden çıkması ve gömülü tampon sendromu yer alır (25). Aynı zamanda yetersiz beslenme, obezite, diyabet, malignite, ilaç tedavisi (immünsüpresif ilaç, kronik kortikosteroid tedavisi) ve uygun yapılmayan PEG bakımı enfeksiyon oluşumuna zemin hazırladığı için NF oluşmasına neden olabilmektedir $(4,25)$. PEG tüpünde aşırı basınç da NF'e neden olur. Tedavisi intravenöz antibiyotiklerle ve acil cerrahi debridman ile yapilır (24). 


\section{Tablo 1. Nekrotizan fasiitin klinik evreleri}

\section{Evre I (erken)}

Klinik özellikler

Palpasyon ile hassasiyet

(görünür deri tutulumunun dıșına uzanan)

Eritem

Şişme

\section{Evre II (orta)}

Bül veya kabarcık formasyonu (seröz sıvı)

\section{Evre III (geç)}

Krepitasyon

Deride his kaybı

Deride renk koyulaşmasına neden olan cilt nekrozu

Kalor (deride isı artışı)

\section{Perkütan Endoskopik Gastrostomi Tüpünün Giriş Yerinin Pansumanı Nasıl Yapılmalıdır?}

Perkütan endoskopik gastrostomi tüpünün ilk pansumanı yerleştirme işleminden 24 saat sonra yapılmalıdır. Cilt bakımı günlük temizliği yumuşak sabun ile yapılmalı, ardından su ile durulanmalı ve gazlı bez ile kurulanmalıdır. Gömülü tampon sendromunu önlemek için plaka saat yönünde ilk bir hafta günlük 360 derece döndürülmelidir. llk bir haftadan sonra pansuman 2 günde bir yapıldığı için her pansuman sırasında plaka 360 derece döndürülmelidir. Gazlı bez Y şeklinde plakanın altına yerleștirilip kapatılmalıdır. Bir hafta sonra, gastrostomi bölgesinin açık bırakılması önerilmektedir. Ayrıca PEG tüpünün yerleştirilmesinden sonra, gastrostomi tüpünün dış plakası, en az 0,5 cm'lik bir ileri geri hareket sağlayacak şekilde konumlandırılmalı ve 24 saat sonra gevşetilmelidir (26-28).

Peristomal enfeksiyonları PEG prosedürü ile ilişkili en sık görülen komplikasyondur ve insidansı \%4-30 arasında değişmektedir. Lokal enfeksiyonun önlenmesi için düzenli cilt bakımı çok önemli olmakla birlikte, bandaj teknikleri de (sıkı bantlama yapılmaması) önemli bir rol oynamaktadır (4). Perkütan endoskopik gastrostomi tüpünün yerleştirilmesinden sonra dış plaka desteğinin yerleştirilmesi de çok önemlidir. Plaka, PEG tüpünün stomaya doğru 1 ile $2 \mathrm{~cm}$ "içeri ve dışar1" hareketine izin verecek şekilde yerleştirilmelidir. Plakanın karın duvarına daha gevşek uygulanması periton sızıntısına neden olmaz. Dış plakanın karın duvarına çok sıkı bir şekilde konumlandırılması, gömülü tampon sendromu veya nekrotizan fasiite neden olabilir (29).

Gastrostomi bölgesinde aşırı granülasyon dokusu gelişebilir. PEG sonrası en sık görülen komplikasyondur ve granülasyon dokusu vakaların \%30'unda görülebilmektedir. Dış plaka ile cilt arasındaki mesafe en az $1 \mathrm{~cm}$ 'lik hareketine izin verecek şekilde olmalıdır. Plakanın bu şekilde olması çekiş olması- nı korur ve enfeksiyon olasıllğını azaltır (26). Granülasyon dokusunun tedavisinde; topikal antimikrobiyal ve düşük doz steroid içeren pomadların kullanımı ile gümüş nitrat çubukları ile koterizasyon uygulanması tedavi seçenekleri olarak açıklanmıştır. Bununla birlikte Kahveci ve ark. 2019 ylındaki çalışmalarında granülasyon dokusunun tedavisinde \%10'luk povidon iyot kullanımının etkili olduğu bildirilmiştir (30). Minör komplikasyonlar arasında yer alan hipergranülasyon doku gelişimi tedavi edilmezse periostomal enfeksiyona, enfeksiyon tedavi edilmez ise majör komplikasyon olan nekrotizan fasiite neden olabilmekte ve nadir de olsa ölümle sonuçlanabilmektedir. PEG bölgesi enfeksiyonu için 5-7 günlük oral geniss spektrumlu antibiyotiklerle tedavi yeterli olabilir. Septik bulgular mevcut ise, lokal yara bakımı ile birlikte intravenöz geniş spektrumlu antibiyotikler gereklidir (26).

Komplikasyonları önlemek ve komplikasyon geliştiğinde erken teşhis ederek tedavisini yapmak, morbidite ve mortalite açısından, PEG bakımında büyük bir öneme sahiptir. Bunun için de; hasta bakımına katılan sağlık personeli ve bakıcılara eğitim ve bilgi sağlamak doğru bakım için gereklidir. Her durumda erken komplikasyonları belirlemek ve tedavi etmek hastalar için güvenlik ve etkinlik sonuçlarını en üst seviyeye çıkaracaktır.

Sonuç olarak; nekrotizan fasiit PEG tüpünün pansumanı ile önlenebilir. Erken fark edilip tedavisinin yapılması ile ölümle sonuçlanması engellebilir. PEG eğitimi veren hemşirelerin komplikasyonlar konusunda bilgi sahibi olmaları ve komplikasyonlar geliştiğinde bakım süreçlerini yönetebilmeleri çok önemlidir. Bu olgu sunumu bize PEG bakımının nekrotizan fasiit gibi ölümle sonuçlanabilecek çok ciddi komplikasyonların erken teşhisi ve etkin tedavi ile önlenebileceğini gözler önüne sermiştir.

\section{"Tüm yazarlar herhangi bir çıkar çatışması olmadığını kabul ederler."}

\section{KAYNAKLAR}

1. Bischoff SC, Austin P, Boeykens K, et al. ESPEN guideline on home enteral nutrition. Clin Nutr 2020;39:5-22

2. Anderloni A, Leoa MD, Barzaghi F, et al. Complications and early mortality in percutaneous endoscopic gastrostomy placement in lombardy: A multicenter prospective cohort study. Dig Liver Dis 2019;51:1380-7.
3. Gauderer M. Twenty years of percutaneous endoscopic gastrostomy: Origin and evolution of a concept and its expanded applications. Gastroint Endosc 1980;50:879-83.

4. Blumenstein I, Shastri YG, Stein J. Gastroenteric tube feeding: Techniques, problems and solutions. World J Gastroenterol 2014;20:8505-24. 
5. Özden D, Karagözoğlu \$, Güler N, Bülbüloğlu S. Evde enteral tüple beslenen hastaların beslenmeye ilişkin yaşadığı sorunlar ve yakınlarının bakım yükü. DEUHFED 2016;9:134-41.

6. Özbaş N, Göçmen Baykara Z. The determination of the level of knowledge of nurses on enteral tube feeding. Journal of Human Sciences 2018;15:359-67.

7. Hemșirelik Yönetmeliği. (2010). 8 Mart Tarihli ve 27515 Sayılı Resmî Gazete.resmigazete@basbakanlik.gov.tr. Erişim tarihi: 15.01.2020.

8. Hacettepe Üniversitesi Nüfus Etütleri Enstitüsü. (2019). 2018 Türkiye Nüfus ve Sağlık Araştırması, Temel Bulgular. Hacettepe Üniversitesi Nüfus Etütleri Enstitüsü, T.C. Cumhurbaşkanlığı Strateji ve Bütçe Başkanlığı ve TÜBıTAK, Ankara, Türkiye.

9. Kaul R, McGeer A, Low DE, Green K, Schwartz B. Population-based surveillance for group A streptococcal necrotizing fasciitis: Clinical features, prognostic indicators, and microbiologic analysis of seventy-seven cases. Ontario Group A Streptococcal Study. Am J Med 1997;103:1824.

10. Das DK, Baker MG, Venugopal K. Increasing incidence of necrotizing fasciitis in New Zealand: A nationwide study over the period 1990 to 2006. J Infect 2011;63:429-33.

11. Psoinos CM, Flahive JM, Shaw JJ, et al. Contemporary trends in necrotizing soft-tissue infections in the United States. Surgery 2013;53:819-27.

12. Khamnuan P, Chongruksut W, Jearwattanakanok K, Patumanond J, Tantraworasin A. Necrotizing fasciitis: epidemiology and clinical predictors for amputation. Int J Gen Med 2015;8:195-202.

13. Glass GE, Sheil F, Ruston JC, Butler PE. Necrotising soft tissue infection in a UK metropolitan 251 population. Ann R Coll Surg Engl 2015;97:46-51.

14. Chuang KL, Liang FW, Shieh SJ, Lu TH. The incidence of necrotizing fasciitis in Taiwan: A nationwide population-based study. Ann Plast Surg 2018;80(2S Suppl 1):S75-S78.

15. Goepfert AR, Guinn DA, Andrews WW, Hauth JC. Necrotizing fasciitis after cesarean delivery. Obstet Gynecol 1997;89:409-12.

16. Gallup DG, Freedman MA, Meguiar RV, Freedman SN, Nolan TE. Necrotizing fasciitis in gynecologic and obstetric patients: a surgical emergency. Am J Obstet Gynecol 2002;187:305-10.

17. Lim YJ, Yong FC, Wong CH, Tan AB. Necrotising fasciitis and traditional medical therapy a dangerous liaison. Ann Acad Med Singapore 2006;35:270-3.
18. Golger A, Ching S, Goldsmith CH, Pennie RA, Bain JR. Mortality in patients with necrotizing fasciitis. Plast Reconstr Surg 2007;119:1803-7.

19. Hefny AF, Eid HO, Al-Hussona M, Idris KM, Abu-Zidan FM. Necrotizing fasciitis: a challenging diagnosis. Eur J Emerg Med 2007;14:50-2.

20. Peer SM, Rodrigues G, Kumar S, Khan SA. A clinicopathological study of necrotizing fasciitis an institutional experience. J Coll Physicians Surg Pak 2007; 17:257-60.

21. Grant DG, Bradley PT, Pothier DD, et al. Complications following gastrostomy tube insertion in patients with head and neck cancer: a prospective multi-institution study, systematic review and meta-analysis. Clin Otolaryngol 2009;34:103-112

22. MacLean AA, Miller G, Bamboat ZM, Hiotis K. Abdominal wall necrotising fasciitis from dislodged percutaneous endoscopic gastrostomy tubes: A case series. Am Surg 2004;70:827-31.

23. Wang YS, Wong CH, Tay YK. Staging of necrotizing fasciitis based on the evolving cutaneous features. Int J Dermatol 2007;46:1036-41.

24. Hucl T, Spicak J. Complications of percutaneous endoscopic gastrostomy. Best Pract Res Clin Gastroenterol 2016;30:769-81.

25. Baloch UB, Noor H, Silverberg M. Abdominal wall necrotizing fascittis: A rare complication of percutaneous gastrostomy. Chest 2018;154:242A-242A

26. Toussaint E, Gossum AV, Ballarin A, Arvanitakis M. Enteral access in adults. Clinical Nutrition 2015;34:350-8.

27. Lord LM. Enteral access devices: types, function, care, and challenges. Nutr Clin Pract 2018;33:16-38.

28. Roveron G, Antonini M, Barbierato M, et al. Clinical practice guidelines for the nursing management of percutaneous endoscopic gastrostomy and jejunostomy (PEG/PEJ) in adult patients. J Wound Ostomy Continence Nurs 2018;45:326-34.

29. DeLegge MD. Enteral access and associated complications. Gastroenterol Clin N Am 2018;47:23-37.

30. Kahveci G, Dağcı S, Atalay R. A different perspective of hypergranulation tissue care in percutaneous endoscopic gastrostomy: A case report and review of the literature. Endoscopy Gastrointestinal 2019;27:65-7. 